\title{
New use of alkaline phosphatase in neonatology
}

\author{
Vlad DIMA ${ }^{1}$, Andreea AVRAMESCU-CALOMFIRESCU ${ }^{1}$, Valentin VARLAS ${ }^{2}$, Luminita PADURARU ${ }^{3}$, \\ Simona VLADAREANU2 \\ ${ }^{1}$ Filantropia Hospital, Bucharest, Romania \\ ${ }^{2}$ "Carol Davila" University of Medicine and Pharmacy, Bucharest, Romania \\ 3 "Gr.T. Popa" University of Medicine and Pharmacy, lasi, Romania
}

\begin{abstract}
Background. Alkaline phosphatase is an enzyme that catalyzes the hydrolysis of esters in an alkaline environment. Four isoenzymes have been identified in the human body: placental alkaline phosphatase (PLALP isoenzyme), intestinal alkaline phosphatase (IAP), hepatic/bone/renal alkaline phosphatase $(L / B / K$ $A L P)$ and germ cell alkaline phosphatase (GCALP). The uses of ALP in neonatology have been intensively studied, and associations have been demonstrated between elevated alkaline phosphatase levels and hypocalcemia and hypophosphatemia in premature infants, the onset of early osteopenia and the occurrence of necrotizing enterocolitis.

Objective. The current study aimed to demonstrate the correlation between elevated alkaline phosphatase levels in blood from the umbilical cord and elevated transcutaneous bilirubin levels that indicated phototherapy.

Material and methods. The study included 250 term newborns within 01-06.2018 and 31 had indication for phototherapy, and 219 without indication for phototherapy, in a tertiary maternity hospital in Bucharest, Romania. Alkaline phosphatase was determined in the umbilical cord serum.

Results. The values of the alkaline phosphatase were from 145 to 417 U/l for the newborns without phototherapy and the treated group was beetween 320 and $602 \mathrm{U} / \mathrm{l}$. The values of the alkaline phosphatase were not influenced by the birth weight, Apgar score, and gender.

Conclusions. Alkaline phosphatase may represent a predictive marker for the need for phototherapy in term neonates, but further extended studies are required on larger groups of patients.
\end{abstract}

Keywords: alkaline phosphatase, transcutaneous bilirubin, phototherapy, term newborn

\section{INTRODUCTION}

Alkaline phosphatase (ALP) is a ubiquitous cell membrane-bound glycoprotein that catalyzes the hydrolysis of phosphate monoestersat an alkaline $\mathrm{pH}$. ALP present in mammals is zinc-containing metalloenzymes, encoded by a multigenic family, and function as dimeric molecules. They contain three metal ions, including two $\mathrm{Zn2}^{+}$ions and one $\mathrm{Mg}^{+}$ion in the active locus, essential for enzymatic activity. They also con- tribute substantially to the conformation of the ALP monomer and indirectly regulate the interactions of the two subunits [1]. Human ALPs can be classified into at least four specific tissue forms or isoenzymes depending on the type of tissue at which they act. Thus, there is placental alkaline phosphatase (PLALP isoenzyme), intestinal alkaline phosphatase (IAP), hepatic/bone/renalalkaline phosphatase (L/B/K ALP) and germ cell alkaline phosphatase (GCALP). The intestinal and placental ALP locus is located near the end of long 
arm of chromosome 2, and the hepatic/bone/renal ALP is located near the end of the short arm of chromosome 1.

Placental ALP is a thermally stable enzyme present in high levels in the placenta. Low levels of this isoenzyme can be identified in normal serum [2]. It can be re-expressed by cancer cells. It is a polymorphic enzyme with over 18 alloenzymes resulting from point mutations in genes. IAP is a partially thermally stable isoenzyme present in high levels in intestinal tissue. Unlike other ALP isoenzymes, the carbohydrate sidechains of IAP do not end in a sialic acid. Isolated forms of fetal and adult intestinal tissues are different. It differs in both carbohydrate content and the protein part itself, suggesting that there is a separate gene locus in humans that encodes ALP during fetal to adult development. This embryonic gene can be re-expressed (but in a modified form) by cancer cells. Germ cell alkaline phosphatase (GCALP) is a thermally stable isoenzyme present in germ cells, embryos- and some neoplastic tissues $[3,4]$. Testicular GCALP appears to localize in the cell membrane of immature germcells, and as other ALP isoenzymes are attached to the cell membrane employing a phosphatidyl-inositol-glycan. Like the gene, placental ALP can be re-expressed by cancer cells.

Hepatic/bone/renal ALP, thermally unstable isoenzyme is the nonspecific form present in the liver/ bones/kidneys or nonspecific tissues (TNSALP form) $[5,6]$. It is expressed in several tissues of the body and is especially abundant in the liver, skeletal and renal tissues. Slight differences in electrophoretic mobility and stability between hepatic/bone/renal ALP in different tissues are attributed to differences in change posttranslational, although their protein portions may encode by separate but associated genes [7].

The general structure of PLAP is a dimer, and each monomer contains 484 residues, four metal atoms, a phosphate ion, and 603 water molecules. Two crystallographic axes link the two monomers. PLAP possesses additional secondary structure elements, comprising an N-terminal helix (residues 9-25), $a$ helix, and a $b$ chain in an extremely different region (residues 208Y280) and a different organization in the 365Y430 domain. In the active site, only the residues that are essential for catalysis retained, the three metal ion sites, M1 (occupied by $\mathrm{Zn}^{2+}$, also called $\mathrm{Zn}^{1}$ ), M2 (occupied by $\mathrm{Zn}^{2+}$; also called $\mathrm{Zn}^{2}$ ) and M3 (occupied by $\left.\mathrm{Mg}^{2+}\right)$, as well as their ligands, while most of the surrounding residues are different.

Half of the enzyme's surface corresponds to three identifiable regions whose sequences vary widely between human types of PA and are absent in non-mammalian enzymes, for example, the long N-terminal a-helix is flexible interfacial loop known as Fcrown_ domain and a fourth metal-binding domain (M4).
The availability of the PLAP structure facilitated the modeling of human germ cell AP isozymes (GCAP), intestinal AP (IAP), and non-tissue-specific AP (TNAP, liver/bone/kidney type), revealing that all the innovative features found in PLAP conserved in humans [8]. The active site is conserved in all species in which an AP has sequenced to date. Structure/function studies comparing PLAP and ECAP structure found a conserved function for those residues that stabilize the active site $\mathrm{Zn}^{1}, \mathrm{Zn}^{2}$ and $\mathrm{Mg}$, metal ions, for example Asp42, His153, Ser155, Glu311, Asp316, His320, Asp357, His358, His360, and His432 [9].

Upon revealing the resolution of the 3D PLAP structure, it was discovered that an additional non-catalytic calcium-binding site appears to be occupied by calcium [8]. This locus is attached to carboxylates from Glu216, Glu270, and Asp285, and the carbonyl Phe269, and a water molecule. This architecture is preserved in all human and mouse APs. All mammalian APs have five cysteine residues (Cys101, Cys121, Cys183, Cys467, and Cys474) per subunit, they form two disulfide bonds, Cys121-Cys183 and Cys467- Cys474, while Cys101 residues remain free [10]. APs appear to have structural similarity to a large number of other enzymes suggesting an involvement in enzyme dimerization. Mutation of cofactor-independent phosphoglycerates (iPGM) has previously identified as a member of the AP superfamily of enzymes based on the conservation of predicted metallic binding residues [11].

Searches for iterative homology led to the identification of similarly conserved regions in phosphopentomutases, AP, and in several previously uncharacterized proteins. All amino acid residues that interact with $\mathrm{Zn}^{1}$ (Asp327, His331, and His412) and $\mathrm{Zn}^{2}$ (Asp51, Asp369, and His370) [12] are conserved in the phosphocarbon-binding proteins of the AP superfamily. On the other hand, ligands to the Mg site of AP are much less conserved, as an E322N substitution is found in phosphopentomutases and iPGM, while Asp153 and Thr155 do not appear to be conserved at all. The reliable preservation of metal-binding residues in both phosphopentomutase and IPGM indicates that both enzymes depend on the metal. APs are known to have phosphotransferase and also phosphodiesterase activities, while iPGM and nucleotide pyrophosphatase/ phosphodiesterase 1 (NPP1) can also function as phosphatases [13].

\section{AIM}

In this study, we aim to make correlations between serum alkaline phosphatase values in umbilical cord blood and transcutaneous bilirubin values at 24 and 48 hours, as well as the establishment of photothera- 
py treatment at high bilirubin values correlated with high alkaline phosphatase values.

\section{MATERIAL AND METHOD}

An observational study was conducted for six months in which 250 newborns registered in "Filantropia” Hospital Bucharest were included in January 2019 - June 2019 (123 males and 127 females).

The study included healthy term newborns, with an appropiate weight for gestational age, with Apgar Score higher than 8 at 1 minute, from investigated pregnancies. The exclusion criteria were: $\mathrm{Rh}$ and $\mathrm{ABO}$ incompatibility, malformations, twins, pathologies identified at birth. An informed consent for participating in this study was obtained from each mother before birth. The ethical approval was obtained before starting the study.

A database was compiled and was analyzed using IBM SPSS 20. The variables were nominal categorical (sex, type of birth) and continuous or discrete quantitative (gestational age, APGAR scoring system, birth weight, alkaline phosphatase values, transcutaneous bilirubin at 24 and 48 hours). For the descriptive characterization of the quantitative variables, measurements of the central tendency (mean, median) and of the variability (standard deviation) were used, and for the qualitative variables, absolute frequencies and percentages/proportions were used. Histograms were used for the graphical summary of the quantitative variables, and for the qualitative ones were used bar type graphs. Depending on the distribution of the values and of the quantitative variables, the t-test was used for independent samples to make a comparison between the values of the averages from the two target populations. When the distribution of the values of a variable was non-parametric, non-parametric tests, respectively Mann-Whitney, were used for comparisons. The significance level considered was $p<$ 0.05 .

ALP was measured from blood collected from the umbilical cord immediately after birth, and the outcome of transcutaneous bilirubin levels monitored for each case, at 24 and 48 hours. Alkaline phosphatase value was obtained by processing blood samples using the Huma Star 300 apparatus by spectrophotometry method. The transcutaneous bilirubin was performed using Jaundice Meter Drager JM-105 (pulse xenon arc lamp) at the sternum. A blood sample of $2 \mathrm{ml}$ was collected in the delivery room in a simple tube, coagulated serum. The complex anticoagulants $\mathrm{Mg2}^{+}$and $\mathrm{Zn2}^{+}$, both necessary in the in vitro ALP activity, should be avoided. Markers of hemolysis, hyperbilirubinemia or hyperlipidemia may also interfere with the accuracy of the test.
In the study were included healthy term newborns, appropriate weigth for gestational age, with Apgar score higher than 8 at 1 minute, from investigated pregnancies. The exclusion criteria were: $\mathrm{Rh}$ and $\mathrm{ABO}$ incompatibility, malformations, twins, pathologies identified at birth. An informed consent was obtained from each mother before birth.

The ethical approval was obtained before starting the sudy.

\section{RESULTS}

Our research included 250 participants and the demographic data of the newborns introduced in the study are summarized in Table 1.

TABLE 1. Demographic data

\begin{tabular}{|l|c|c|c|c|}
\hline & N & Minimum & Maximum & Average \pm SD \\
\hline $\begin{array}{l}\text { Gestational } \\
\text { age (weeks) }\end{array}$ & 250 & 37 & 41 & $38.96 \pm 1.36$ \\
\hline Weight (g) & 250 & 2500 & 4050 & $3050.40 \pm 302.69$ \\
\hline $\begin{array}{l}\text { Apgar score } \\
\text { 1 minute }\end{array}$ & 250 & 8 & 10 & $9.12+/-0.53$ \\
\hline $\begin{array}{l}\text { Apgar score } \\
\text { 5 minutes }\end{array}$ & 250 & 9 & 10 & $9.64+/-0.48$ \\
\hline
\end{tabular}

Alkaline phosphatase (ALP) values ranged between $145 \mathrm{U} / \mathrm{l}$ and $602 \mathrm{U} / \mathrm{l}$ with an average $\pm \mathrm{SD}$ of $282.69 \pm 62.15 \mathrm{U} / \mathrm{I}$ and a median of $298 \mathrm{U} / \mathrm{I}$. The neonates were divided in two groups depending on the need of tratament (phototherapy) for hiperbilirubinemia.

In subjects who did not require phototherapy alkaline phosphatase $(\mathrm{U} / \mathrm{I})$ values ranged from a minimum of $145 \mathrm{U} / \mathrm{l}$ to $417 \mathrm{U} / \mathrm{l}$, with a mean \pm SD of $268.95 \pm$ $48.61 \mathrm{U} / \mathrm{I}$ and a median of $288.75 \mathrm{U} / \mathrm{I}$. In subjects requiring phototherapy alkaline phosphatase values were between $320 \mathrm{U} / \mathrm{I}$ and $602 \mathrm{U} / \mathrm{I}$ with a mean $\pm \mathrm{SD}$ of $379.73 \pm 61.52 \mathrm{U} / \mathrm{I}$ and a median of 356 . A t- test showed that the mean values alkaline phosphatase in subjects requiring phototherapy were significantly higher than subjects for whom no phototherapy performed $(t=-11.47, p=.00$ with a significant Cohen's effect size of 1.99).

The newborns registered in the study had normal weight for gestational age, at term without other associated pathologies, coming from investigated pregnancies and obtaining consent from one of the parents. Thus, a comparison could be made between gestational age, birth weight, transcutaneous bilirubin values, and alkaline phosphatases values without presenting favorable conditions for jaundice. There was no significant statistical difference regarding gestational age or birthweight between the two groups ( $\mathrm{Ta}$ ble 2). Alkaline phosphatases values were significantly higher in the study group $(p=0.00)$. 


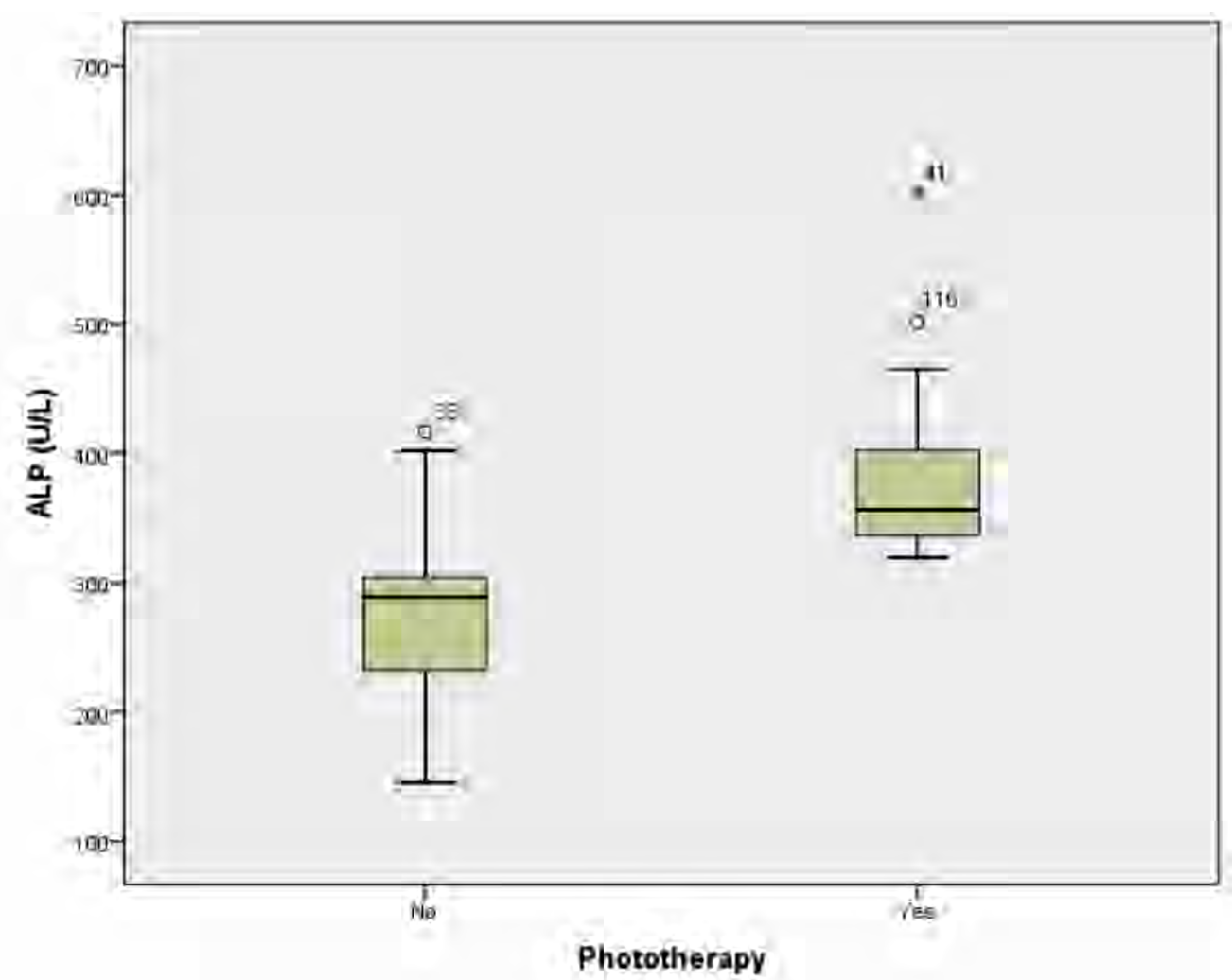

FIGURE 1. Alkaline phosphatase values depending on the need for phototherapy

TABLE 2. Comparison of gestational age, birth weight and alkaline phosphatase between the treatment group vs. the group without treatment

\begin{tabular}{|l|c|c|c|}
\hline & $\mathrm{N}$ & $\mathrm{M} \pm \mathrm{SD}$ & $\mathrm{p}$ \\
\hline \multirow{2}{*}{$\begin{array}{l}\text { Gestational age (weeks) } \\
\text { - Without phototherapy }\end{array}$} & \multicolumn{3}{|c|}{} \\
\cline { 2 - 3 } - With phototherapy & 219 & $38.92 \pm 1.36$ & .29 \\
\cline { 2 - 3 } & 31 & $39.19 \pm 1.33$ & \\
\hline \multirow{2}{*}{$\begin{array}{l}\text { Weight at birth (g) } \\
\text { - Without phototherapy }\end{array}$} & \multicolumn{3}{|c}{} \\
\cline { 2 - 3 } - With phototherapy & 219 & $3043.15 \pm 303.23$ & .31 \\
\cline { 2 - 3 } $\begin{array}{l}\text { Alkaline phosphatase (U/I) } \\
\text { - Without phototherapy }\end{array}$ & 31 & $3101.61 \pm 298.74$ & \\
\cline { 2 - 3 } - With phototherapy & 219 & $268.95 \pm 48.61$ & .00 \\
\cline { 2 - 3 } & 31 & $379.73 \pm 61.52$ & \\
\hline
\end{tabular}

In addition the values of alkaline phosphatase were analysed depending on the Apgar score. In subjects with an APGAR score of 8 measured at 1 minute, alkaline phosphatase (FAL) values were between $195.7 \mathrm{U} / \mathrm{l}$ and $403 \mathrm{U} / \mathrm{I}$ with a mean +/- SD of $281.09+/-59.23 \mathrm{U} / \mathrm{I}$ and a median of 288.6. In subjects with a score of 9 - FAL values were between $156 \mathrm{U} / \mathrm{I}$ and $602.1 \mathrm{U} / \mathrm{I}$ with a mean +/- SD of $287.67+/-62.47 \mathrm{U} / \mathrm{l}$ and a median of $298.6 \mathrm{U} / \mathrm{l}$. In subjects with a score of 10 , FAL values were between $145.39 \mathrm{U} / \mathrm{l}$ and $402 \mathrm{U} / \mathrm{I}$ with a mean $+/-\mathrm{SD}$ of $266.35+/-$ 60.52 and a median of $283.3 \mathrm{U} / \mathrm{l}$. The Kruskal-Wallis test showed that there was no statistically significant difference between the medians of the FA values according to the APGAR score at 1 minute $(X 2=2.94, p=.23)$.

FAL values for subjects with an APGAR score of 9 at 5 minutes were between $187.6 \mathrm{U} / \mathrm{I}$ and $602.1 \mathrm{U} / \mathrm{I}$ with a mean +/- SD of $295.79+/-59.62 \mathrm{U} / \mathrm{l}$ and a median of $299.8 \mathrm{U} / \mathrm{l}$. FAL values in subjects with this score of 10 were between $145.39 \mathrm{U} / \mathrm{l}$ and $501.45 \mathrm{U} / \mathrm{I}$ with a mean +/- SD of $275.44+/-62.51 \mathrm{U} / \mathrm{l}$ and a median of $294 \mathrm{U} / \mathrm{l}$. The Mann-Whitney test showed that there was a statistically significant difference between the median FAL values as a function of the 5-minute APGAR score $(U=5,839, p=0.01)$.

The Scatter graph shows that there was no linear relationship between birth weight and FAL values.

In those whose birth was spontaneous, FAL values were between $145.39 \mathrm{U} / \mathrm{I}$ and $602.1 \mathrm{U} / \mathrm{I}$ with a mean +/- SD of 285.61 +/- $66.98 \mathrm{U} / \mathrm{l}$ and a median of $298 \mathrm{U} / \mathrm{l}$. In those whose birth was by caesarean section, FAL values were between $156 \mathrm{U} / \mathrm{l}$ and $408.7 \mathrm{U} / \mathrm{l}$ with a mean +/- SD of $278.31+/-54.27 \mathrm{U} / \mathrm{l}$ and a median of $298 \mathrm{U} / \mathrm{l}$. The Mann-Whitney test showed that there was no statistically significant difference between the median alkaline phosphatase values depending on the mode of birth $(U=7,298.5, p=0.69)$.

Chi-square test showed no statistical correlation between the gender of the newborns and the need of phototherapy (Table 3).

TABLE 3. Correlation between gender of the neonates and the need of phototherapy $\left(X^{2}=1.11, p=0.29\right)$

\begin{tabular}{|l|l|c|c|c|}
\hline \multicolumn{2}{|c|}{} & \multicolumn{2}{|c|}{ Phototherapy (No/Yes) } & \multirow{2}{*}{ Total } \\
\cline { 3 - 4 } \multicolumn{2}{|c|}{} & No (n= 219) & Yes (n= 31) & \\
\hline \multirow{2}{*}{ Gender } & Female & 114 & 13 & 127 \\
\cline { 2 - 4 } & Male & 105 & 18 & 123 \\
\hline
\end{tabular}




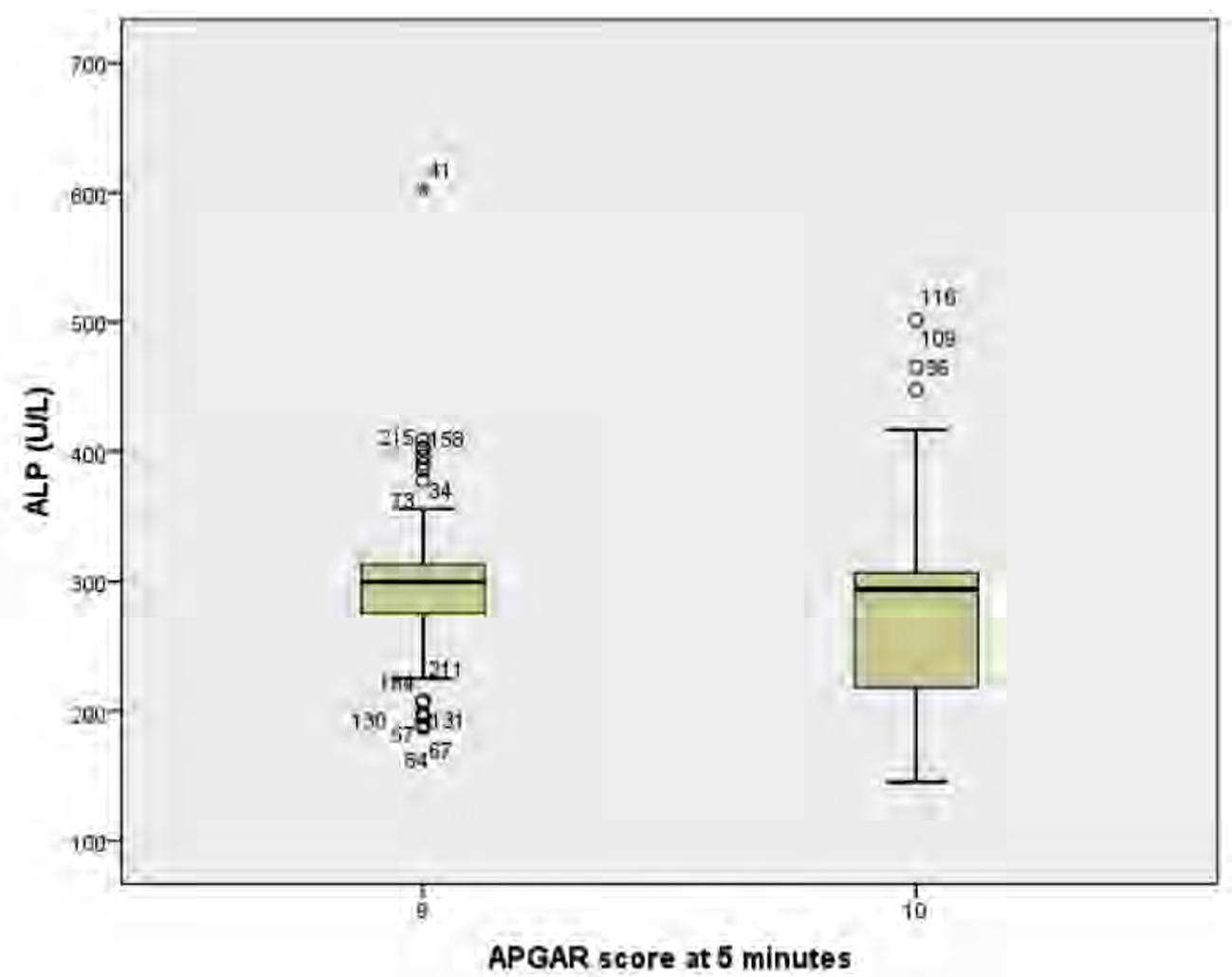

FIGURE 2. Distribution of alkaline phosphatase values according to APGAR score at 5 minute

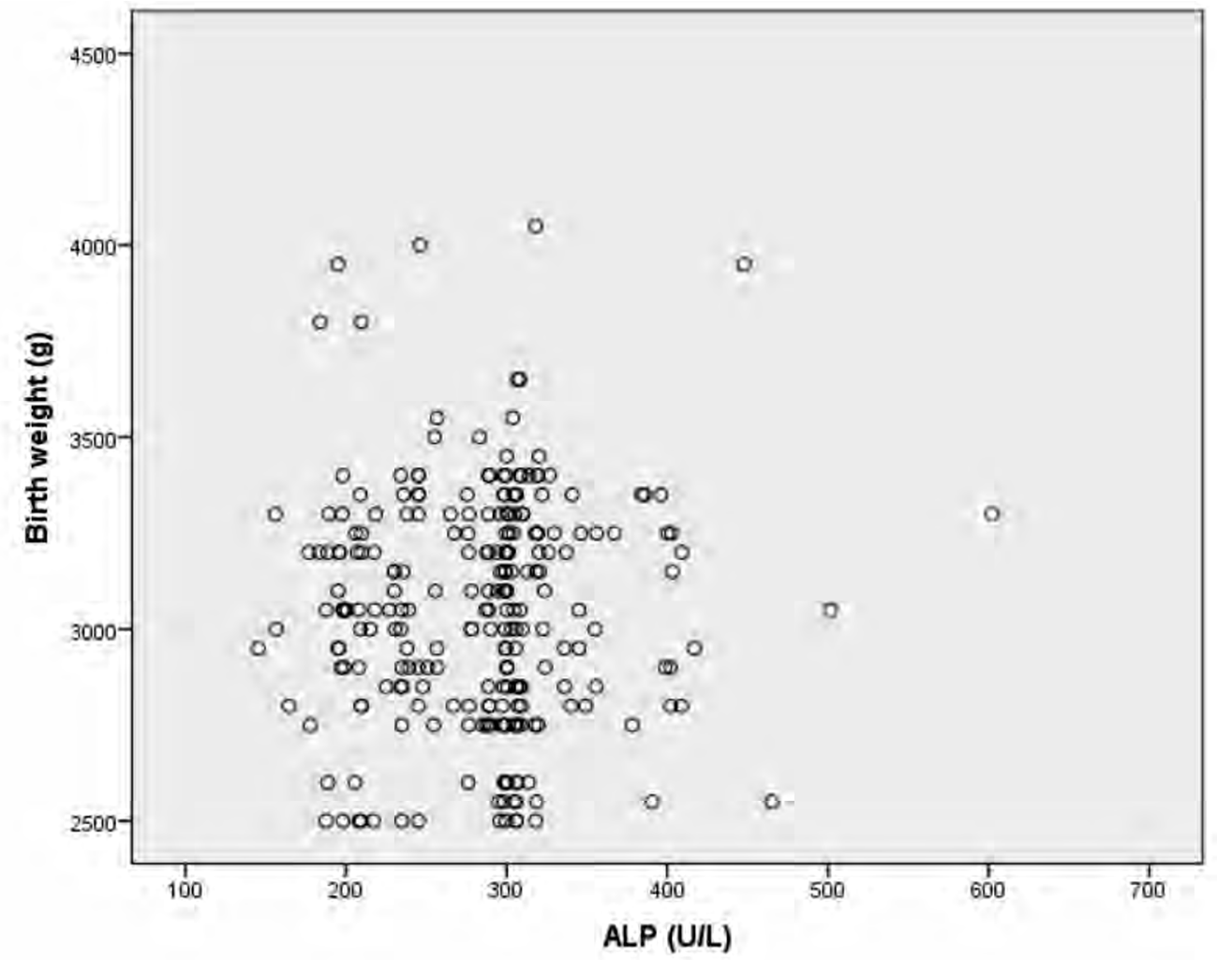

FIGURE 3. Correlation between FAL values and birth weight

\section{DISCUSSIONS}

ALP reported in U/I, with a test-dependent reference range. This range varies according to age and sex: it is generally about $150-300 \mathrm{U} / \mathrm{l}$ in newborns, but as full as $60-450 \mathrm{U} / \mathrm{l}$ in men at puberty. Cases with an elevated level of bilirubin measured transcutaneously required phototherapy according to the nomogram in 


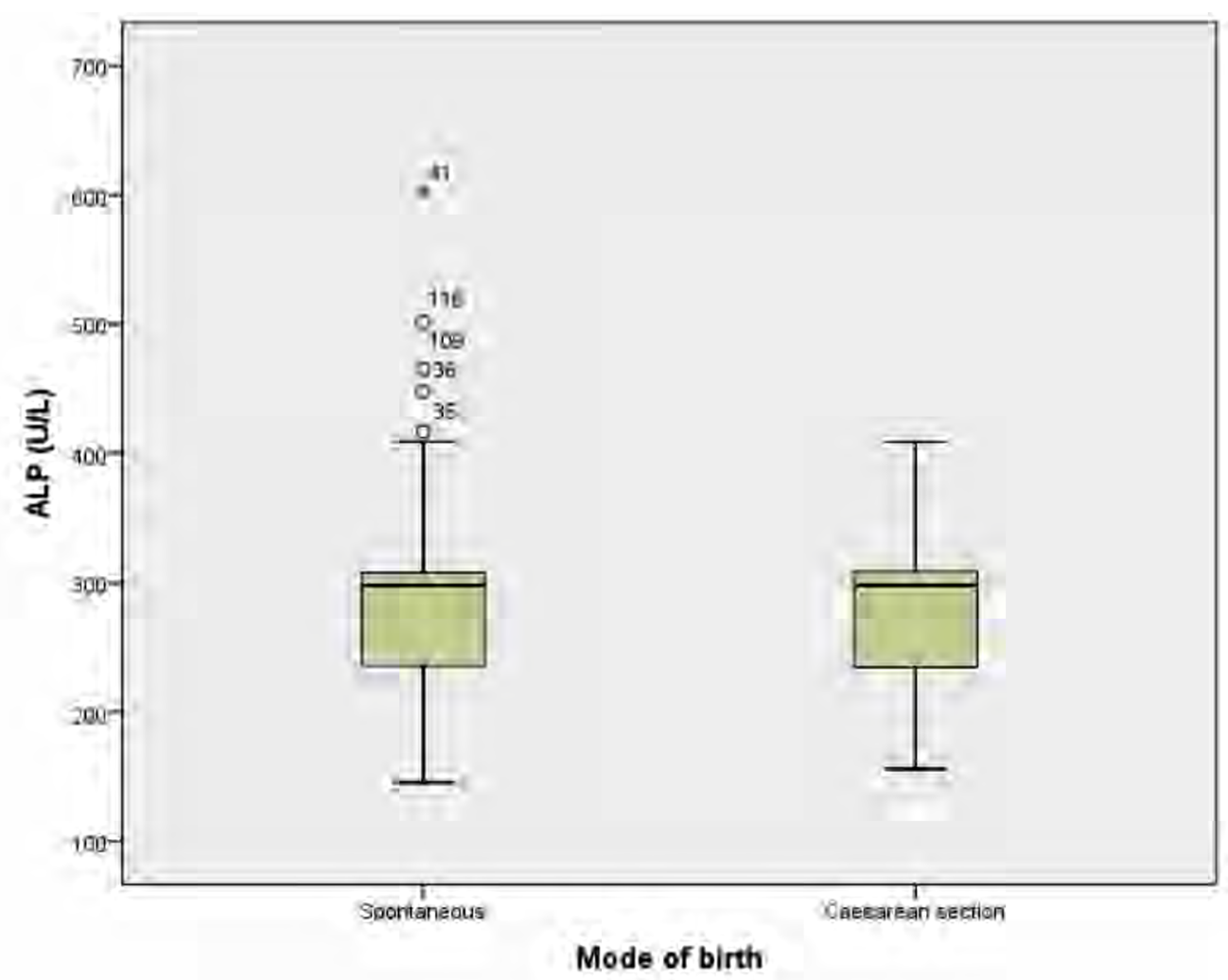

FIGUR 4. Distribution of alkaline phosphatase values according to the mode of birth

the study by Sotirios et al. The values from which it proved necessary to institute phototherapy were, acccording to Sotirios et al., $9 \mathrm{mg} / \mathrm{dl}$ at 24 hours of life and $13 \mathrm{mg} / \mathrm{dl}$ at 48 hours of life [14].

Alkaline phosphatase has been frequently cited in the literature for studies associated with premature bone metabolic disease. Studies in preterm infants have shown associations between high levels of ALP and low plasma levels of phosphorus and high levels of calcium [15]. Both used as serum markers of „current mineral status“, phosphorus being essential for muscle mass accumulation. Retrospective studies have shown a linear association between ALP levels and serum phosphorus levels. Variation in the handling of calcium and renal phosphorus reduces their reliability as markers of current mineral status in terms of underlying bone deposits. Similar problems arise concerning the use of ALP as a marker of current mineral status. Thus, even if the general condition of the minerals remain weak, serum phosphorus, calcium, and ALP can be normal [16].

Serum alkaline phosphatase (ALP), serum phosphorus and serum calcium activity were previously used in screening osteopenia in premature infants. Increased ALP, decreased phosphorus and serum calcium has been associated with an increased risk of MBD (metabolic bone disease) of prematurity. Correlations between skeletal osteopenia, low birth weight, de- creased gestational age, decreased enteral nutrition, and elevated serum ALP in infants weighing $<1,500 \mathrm{~g}$ at birth have been reported in the literature.Serum phosphorus as screening test remains a challenge [17].

Studies have also cited that intestinal alkaline phosphatase (IAP) is involved in the multifactorial mechanisms of necrotizing enterocolitis (NEC). IAP is an endogenous enzyme in the brush of the enterocyte, detoxifies LPS lipopolysaccharide by dephosphorylating the lipid-A fragment, thus preventing its binding to receptor 4 (TLR-4). In the absence of IAP, intestinal inflammation exacerbates and replacement or supplementation of IAP prevents intestinal inflammation and endotoxemia [18].

Other studies have shown a correlation between elevated umbilical cord ALP and elevated bilirubin in the newborn. However, these studies were performed on populations in the Middle East, not in Europe $[19,20]$, and used serum bilirubin measurement instead of transcutaneous measurement of bilirubin. Also, this is the most extensive case study (250 neonates) for this research topic.

Our study shown that elevated alkaline phosphatase values correlated with elevated transcutaneous bilirubin levels and the use of phototherapy. Taking into account the existing studies on this topic [20], we can conclude that the hypothesis of a correlation between elevated ALP values in the umbilical cord and 
elevated bilirubin values is confirmed, regardless of the geographical or populational area, or of the method used to measure transcutaneous bilirubin levels. We found no correlations between ALP levels and gestational age or birth weight; also we found no correlations between the gender of the neonates and the need of phototherapy. The advantages of using the ALP values from the umbilical cord will be a shorter stay in the hospital due to the clear statistical correlation between the ALP values and the need for phototherapy (lower levels of ALP will indicate no need for phototherapy thus the newborn will have an earlier discharge from the hospital) and the method used for determining the values of bilirubin generates no pain for the newborn.

For the use of ALP as a predictive factor future research should also focus on lower gestational ages that is known to be a risk factor for early neonatal jaundice with potential severe consequences.

\section{CONCLUSIONS}

Neonatal jaundice is a common problem that requires prompt treatment and it is necessary to determine predictive factors and we can afirm that the elevated alkaline phosphatase values from the umbilical cord correlated with elevated transcutaneous bilirubin levels and the use of phototherapy.

Alkaline phosphatase may represent a predictive marker for hyperbilirubinemia and the need of phototherapy in term neonates, but further extended studies are required on larger groups of patients.

Conflict of interest: none declared Financial support: none declared

\section{REFERENCES}

1. Hoylaerts MF, Manes T, Millan JL. Mammalian alkaline phosphatases are allosteric enzymes. J Biol Chem. 1997;272:22781-7.

2. Tsai LC, Hung MW, Chen YH, Su WC, Chang GG, Chang TC. Expression and regulation of alkaline phosphatases in human breast cancer MCF-7 cells. Eur J Biochem. 2000;267:1330-9.

3. Millan JL, Manes R. Seminoma-derived nagao isozyme is encoded by a germ cell alkaline phosphatase gene. Proc Natl Acad Sci. 1988;85:3024-8.

4. Hofmann MC, Jeltsch W, Brecher J, Walt H. Alkaline phosphatase isozymes in human testicular germ cell tumors, precancerous stage, and three related cell lines. Cancer Res. 1989;49:4696-700.

5. McComb RB, Bowers GN, Posen S. Alkaline phosphatase. New York: Plenum Publishing Corp; 1979.

6. Harris H. The harvey lectures: series 76 . New York: Academic; 1986. p. 95-123.

7. Sharma U, Pal D, Prasad R. Alkaline Phosphatase: An Overview. Ind J Clin Biochem. 2014;29(3):269-278.

8. Kozlenkov A, Manes T, Hoylaerts MF, Millan $\mathrm{JL}$. Function assignment to conserved residues in mammalian alkaline phosphatases. J Biol Chem. 2002; 277:22992Y9.
9. Le Du MH, Millan JL. Structural evidence of functional divergence in human alkaline phosphatases. J Biol Chem. 2002; 277:49808Y14

10. Galperin MY, Bairoch A, Koonin EV. A superfamily of metalloenzymes unifies phosphopentomutase and cofactorindependent phosphoglycerate mutase with alkaline phosphatases and sulfatases. Protein Sci. 1998;7:1829Y35.

11. Stec B, Holtz KM, Kantrowitz ER. A revised mechanism for the alkaline phosphatase reaction involving three metal ions. $J \mathrm{Mol}$ Biol. 2000;299:1303Y11.

12. Rezende AA, Pizauro JM, Ciancaglini P, Leone FA. Phosphodiesterase activity is a novel property of alkaline phosphatase from osseous plate. Biochem J. 1994; 301:517Y22.

13. Gijsbers R, Ceulemans H, Stalmans W, Bollen M. Structural and catalytic similarities between nucleotide pyrophosphatases/ phosphodiesterases and alkaline phosphatases. J Biol Chem. 2001; 276:1361Y8.

14. Fouzas S, Mantagou L, Skylogianni E, Mantagos S, Varvarigou A. Transcutaneous Bilirubin Levels for the First 120 Postnatal Hours in Healthy Neonates. Pediatrics. 2010;125(1):e52-e57.

15. Tinnion RJ, Embleton ND. How to use... alkaline phosphatase in neonatology. Arch
Dis Child Educ Pract Ed. 2012;97(4):157163.

16. Hung YL, Chen PC, Jeng SF, et al. Serial measurements of serum alkaline phosphatase for early prediction of osteopaenia in preterm infants. J Paediatr Child Health. 2011;47:134-9.

17. Backström MC, Kouri T, Kuusela AL, et al. Bone isoenzyme of serum alkaline phosphatase and serum inorganic phosphate in metabolic bone disease of prematurity. Acta Paediatr. 2000;89:867-73.

18. Tuin A, Huizinga-Van der Vlag A, van Loenen-Weemaes AM, Meijer DK, Poelstra $\mathrm{K}$. On the role and fate of LPS dephosphorylating activity in the rat liver. Am J Physiol Gastrointest Liver Physiol. 2006;290:G377.

19. Al Assal HM, Hablas HR, Afia AAE, Khedr MAA, El Kzaz HMAE. Utility of Cord Blood Alkaline Phosphatase Enzyme as a Predictor of Significant Neonatal Jaundice in Well Term Infants. N Y Sci J. 2017;10(4):7074.

20. Ahmadpour-Kacho M, Zahed Pasha Y, Haghshenas M, Akbarian Rad Z, Firouzjahi A, Bijani A, Dehvari A, Baleghi M. Cord Blood Alkaline Phosphatase as an Indicator of Neonatal Jaundice. Iran J Pediatr. 2015 Oct;25(5):e718. 